\title{
Chronic Aseptic Meningitis in a Patient with Systemic Lupus Erythematosus
}

\author{
Marcelo Elias Lancman, Hripsime Mesropian and Rubens Jorge Granillo
}

\begin{abstract}
Chronic aseptic meningitis is a rare manifestation of systemic lupus erythematosus. It may occur early in the course of the disease and sometimes may be the initial symptom. We report a patient with chronic aseptic meningitis associated with systemic lupus erythematosus. Magnetic resonance imaging showed several ischemic lesions and an appearance which was compatible with chronic inflammation of the ependyma of the lateral ventricles.
\end{abstract}

RÉSUMÉ: Méningite aseptique chronique chez un patient atteint de lupus érythêmateux aigu disséminé La méningite chronique aseptique est une manifestation rare du lupus érythémateux aigu disséminé. Elle peut survenir tôt dans l'évolution de la maladie et peut parfois en étre le premier symptôme. Nous rapportons les cas d'un patient atteint de méningite chronique aseptique associée à un lupus érythémateux aigu disséminé. L'imagerie par résonance magnétique a montré plusieurs lésions ischémiques et un aspect compatible avec une inflammation chronique de l'épendyme des ventricules latéraux.

Can. J. Neurol. Sci. 1989; 16: 354-356

Central nervous system (CNS) involvement in patients with systemic lupus erythematosus (SLE) is common, occurring in between $20-75 \%$ of cases. 1.2 Although any part of the central and peripheral nervous system may be involved, one of the least common manifestations is chronic aseptic meningitis. It may occur early in the course of the disease, and at times can be the initial symptom, ${ }^{3}$ in contrast to bacterial meningitis which appears as a late complication in association with corticosteroid therapy. We report here a patient with chronic aseptic meningitis as a manifestation of SLE, and discuss the magnetic resonance imaging (MRI) findings which were compatible with that diagnosis. We are not aware of any previous publications describing the MRI findings in chronic aseptic meningitis associated with SLE.

\section{CASE RePORT}

A 45-year-old white woman first presented in 1981 with leukopenia. In 1983 she was admitted to her local hospital for myocarditis. No cause was identified for either disorder. In January 1986 she experienced four episodes of dysarthria, each lasting for one hour. In June 1986 she developed an episode of weakness and paresthesiae of the lower extremities. The deficit resolved fully without sequelae after a few hours. In November 1986 she suffered abrupt loss of consciousness, recovering with a left hemiparesis which partially resolved over 24 hours. However, there was persisting left leg weakness and numbness and severe right fronto-temporal headache. A few months later these symptoms were accompanied by the onset of fatigue, malaise, and nocturnal fevers. In March 1987 she noted progressive right lower extremity weakness and an increase in the severity of headache and fatigue. She was admitted to another hospital where a cranial CT scan of the head and cerebral angiography were performed, with normal tindings.

The patient was admitted to our hospital in January 1988. Neurologic evaluation demonstrated neck stiffness, bilateral weakness of the legs, more pronounced on the left, spasticity and urinary incontinence. Laboratory studies showed lynphopenia of $1000 / \mathrm{mm}^{3}$, ESR of $40 \mathrm{~mm} / \mathrm{hr}$, serum albumin of $3.20 \mathrm{~g} / \mathrm{dl}$ and gammaglobulin of $1.52 \mathrm{~g} / \mathrm{dl}$. Urinalysis demonstrated proteinuria of $1.08 \mathrm{~g} / \mathrm{l}$, and pyuria. Lumbar puncture revealed the following CSF findings: glucose $7 \mathrm{mg} \%$ (serum glucose $88 \mathrm{mg} \%$ ), protein $311 \mathrm{mg} / \mathrm{dl}, 140$ leukocytes with $76 \%$ lymphocytes. Immunoelectrophoresis of the CSF proteins demonstrated a polyclonal elevation of gammaglobulin with $\operatorname{lgG}$ of $145 \mathrm{mg} / \mathrm{dl}, \operatorname{lgA}$ $11 \mathrm{mg} / \mathrm{dl}$, and IgM $4.2 \mathrm{mg} / \mathrm{dl}$. Gram stain, India lnk preparation, routine bacterial and fungal cultures, viral and fungal serology, Huddleson reaction and cytology studies were all negative. Antinuclear antibody (ANA) was positive with a titer of $1 / 500$ in a homogeneous pattern, LE cell prep. was positive, VDRL was positive with a negative FTA-abs, anti-DNA was negative and cryoglobulin and rheumatoid factor were negative. A second lumbar puncture one month later, prior to initiating treatment revealed CSF glucose of $32 \mathrm{mg} \%$ (serum glucose $90 \mathrm{mg} \%$ ), protein of $320 \mathrm{mg} \%, 160$ leukocytes. As with the first lumbar punclure Gram stain, India Ink preparation, routine bacterial and fungal cultures, viral and fungal serology and cytology studies were all negative. On the basis of the clinical and laboratory findings a diagnosis of chronic meningitis associated with SLE was made.

An MRI scan of the brain, cervical and thoracic spine was performed. Transaxial, coronal and sagittal planes and appropriate sequences for $\mathrm{T} 1$ and $\mathrm{T} 2$-weighted images were obtained. The spinal column was normal. There was evidence of cerebral atrophy. A right fronto-temporal hypointense area was observed on the Tl-weighted image (Figure 1). On the T2-weighted image this area was hyperintense and changed in form and size (Figure 2). The temporal insula was found to be compromised, without mass effect. The sequences on the T2-weighted images showed multiple hyperintense rounded images

From the Department of Neurology, Italian Hospital, Buenos Aires, Argentina

Received November 22, 1988. Accepted in final form May 7, 1989

Reprint requests to: Rubens Jorge Granillo, Department of Neurology, Italian Hospital, Gascon 450, Buenos Aires, Argentina (1181) 


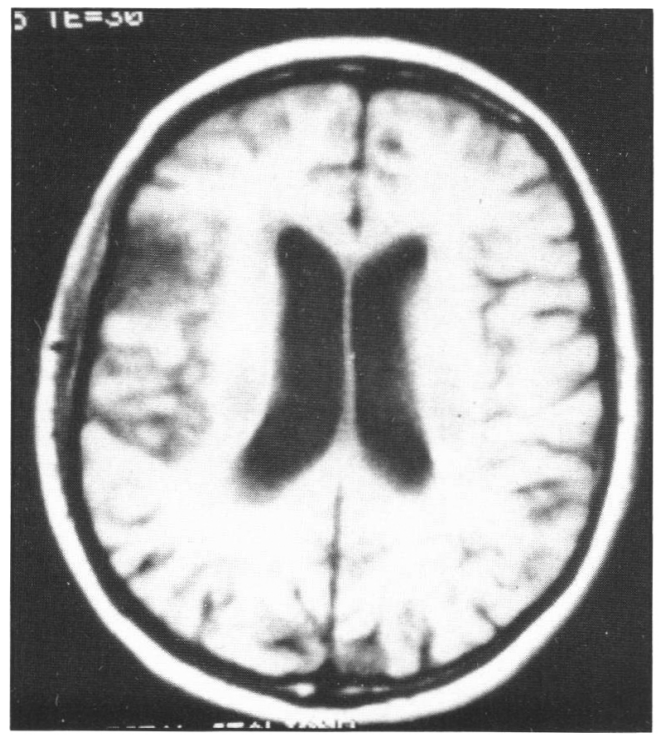

Figure I - Axial Tl-weighted image revealing a righ fronto-temporal hypointense area and cerebral atrophy.

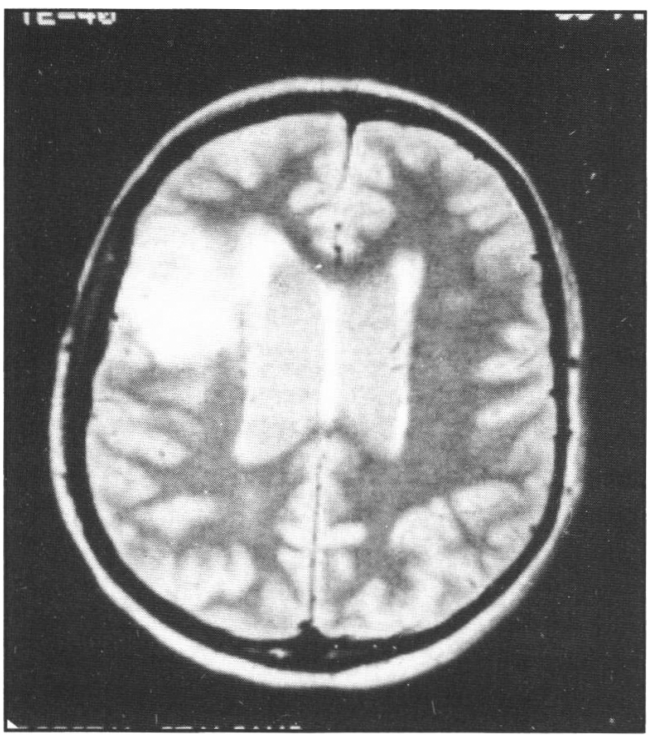

Figure 2 - Axial T2-weighted image showing the right fromto-temporal and the subependymal white matter to be hyperintense at the level of the interventricular septum and the convexity of the ventricles, especially on the right.

located in the following areas: anterior and inferior portions of the right optic thalamus (Figure 3), hypothalamus close to the right side of the floor of the third ventricle, inferior portion of the right frontal lobe close to the suprasellar cistern, anterior limb of the right internal capsule, and subcortical regions of the right frontal, left frontal and left temporal lobes. The ependyma and subependymal white matter were observed to be hyperintense on the T2-weighted images at the level of the intraventricular septum and the convexity of the ventricles, especially on the right. The frontal cuts showed the relation of the right fronto-temporal image with the periventricular lesion. No abnormalities were observed in the brainstem (Figures 1,2,3).

Treatment with methylprednisolone $(80 \mathrm{mg} / \mathrm{day})$ was initiated, and the patient was discharged. She returned to her hometown and followup has not been possible.

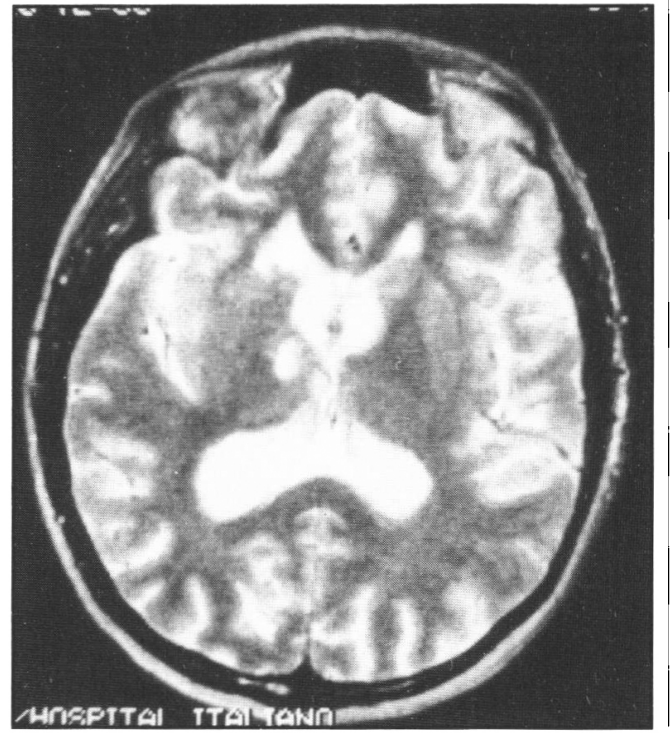

Figure 3 - Axial T2-weighted image revealing hyperintense rounded image located in the anterior portion of the right optic thalamus.

\section{Discession}

Aseptic meningitis is a rare manifestation in SLE patients with CNS involvement.3.4.5 Although meningeal involvement can be the initial, or rarely the only symptom 6 in SLE, it is usually associated with diffuse neurological disease, as in our patient, in whom it was preceded by various episodes of neurological deficits of vascular type presumably caused by lupus vasculopathy. She also had a past history of leukopenia and myocarditis which could have been manifestations of SLE.

The diagnosis of chronic aseptic meningitis secondary to SLE was based on the three month history of headaches and fever, with nuchal rigidity on physical exam, serologic evidence of SLE and CSF abnormalities suggestive of meningeal inflammation without identification of an infectious etiology.

The CSF studies revealed an elevated protein, pleocytosis with striking lymphocytosis and a marked decrease of glucose. Decreased CSF glucose in aseptic meningitis associated with SLE is unusual, with only one prior case reported.?

Cerebral angiography in lupus patients with CNS involvement sometimes reveals arterial beading, but the majority of cases including our patient, show no abnormalities, presumably because the vessels affected by lupus vasculopathy are too small to be visualized by contrast studies. ${ }^{6}$

The CT of the brain was also normal despite obvious neurological involvement. This test shows abnormalities in $65-75 \%$ in CNS lupus patients with overt neurological involvement at the time of CT scanning. $10,11.12$

The MRI in this case revealed three types of lesions: (a) Presumed ischemic lesions seen with $\mathrm{Tl}$-weighted images in the right temporal lobe and right thalamus, (b) possible demyelinating lesions seen with T2-weighted images not corresponding to those mentioned above (these could be due to chronic hypoxia secondary to lupus vasculopathy), and (c) chronic inflammation seen in the lateral ventricular ependyma (ventriculitis). This correlates with the patient's clinical course and laboratory findings. 
MRI appears to be a very sensitive technique for detecting CNS lesions in SLE which are not demonstrated by other methods. These findings correlate with those described by Aisen et al who found MRI to be more sensitive than CT scanning in patients with CNS lupus. ${ }^{13}$ Increased MRI signal suggestive of ventriculitis as seen in our patient has only been described in CNS infections with meningitis. ${ }^{14}$

Current thinking implicates two immunopathogenic mechanisms for the clinical manifestations of CNS lupus. 15 The action of antineuronal autoantibodies may account for the diffuse and partially reversible neuropsychiatric manifestations and seizures of SLE. $6.16 .17 .18,19.20$ An immune complex mediated vasculopathy appears to be responsible for focal ${ }^{16}$ neurologic damage, as occurred in our patient. Pathologic studies of the nervous system often demonstrate a noninflammatory vasculopathy with thickening of the walls of small vessels by intimal proliferation. 1,5 The precise causative mechanism for the damage in the small cerebral vessels is unclear. In addition to the lesions secondary to immune mediated vasculopathy, circulating lupus anticoagulant may produce thrombotic complications. ${ }^{21}$ True vasculitis of the CNS in lupus patients with invasion of vessel walls by inflammatory cells and with fibrinoid necrosis is extremely uncommon. 1.5

The pathogenesis of aseptic meningitis in SLE is unclear. It has been suggested that deposition of antigen-antibody immune complexes in the choroid plexus plays a major role in the CNS manifestations of SLE, 22 although such deposits have been found in other lupus patients without evidence of neurological involvement. ${ }^{23}$ Low $\mathrm{C} 4$ levels ${ }^{24}$ and DNA-anti-DNA complexes ${ }^{25}$ have been found in the cerebrospinal fluid of some patients. On the basis of these findings hypotheses have been proposed to explain the CNS involvement in SLE meningitis. According to some authors ${ }^{25}$ this could be caused by the passage of antigen-antibody complexes across the blood-brain barrier into the choroid plexus.

Based on the clinical and MRI findings we concluded this was a SLE patient with focal involvement of the CNS due to vasculopathy and a lupus chronic aseptic meningitis.

\section{ACKNOWLEDGMENTS}

The authors thank Dr. Gustavo Lopez, Dr. Enrique Soriano and Dr. Carol Patrick for their help in the preparation of this manuscript.

\section{REFERENCES}

1. Johnson RT, Richardson EP. The neurological manifestations of systemic lupus erythematosus. A clinical pathological study of 24 cases and review of literature. Medicine 1968; 47: 337-367.

2. Dubois L. Lupus Erythematosus. Los Angeles: University of Southern California Press, 2d ed, 1974.

3. Canoso J, Cohen A. Aseptic meningitis in systemic lupus erythematosus: report of three cases. Arthritis Rheum 1975; 18: 369374.
4. Sergent J, Lockshin $\mathbf{M}$, Klempner $\mathbf{M}$, et al. Central nervous system disease in systemic lupus erythematosus: therapy and prognosis. Am J Med 1975; 58: 644-654.

5. Ellis SG, Verity MA. Central nervous system involvement in systemic lupus erythematosus. A review of neuropathologic findings in 57 cases, 1955-1977. Semin Arthritis Rheum 1979; 8: 212-221.

6. Nadeau SE, Watson RT. Neurologic manifestations of vasculitis and collagen vascular syndromes. In: Baker AB and Baker LH, eds. Clinical Neurology; Vol. 4; Philadelphia: Harper and Row 1984; chapter 59.

7. Finelli PF, Yockey CC, Hebert AJ. Recurrent aseptic meningitis in an elderly man: unusual prodrome of systemic lupus erythematosus. JAMA 1976; 235: 1142-1143.

8. Appenzeller O, Williams RC. Cerebral Lupus Erythematosus Editorial Notes. Ann Intern Med 1979; 90: 430-431.

9. Hughs GRV. Central nervous system lupus: diagnosis and treatment. J Rheumatol 1980; 7: 405-411.

10. Gonzalez-Scarano F, Lisak RP, Bilaniuk LT, et al. Cranial CT in the diagnosis of SLE. Ann Neurol 1979; 5: 158-165.

11. Gaylis NB, Altman RD, Ostrov S, et al. The selective value of CT of the brain in cerebritis due to SLE. J Rheumatol 1982; 9: 850854.

12. Carette $\mathrm{S}$, Urowitz MB, Grossman $\mathrm{H}$, et al. Cranial computerized tomography in SLE. J Rheumatol 1982; 9: 855-859.

13. Aisen AA, Gabrielsen TO, McCune WJ. MR imaging of systemic lupus erythematosus involving the brain. AJR 1985; 144: 10271031.

14. Davidson HD, Steiner RE. Magnetic resonance imaging in infections of the central nervous system. Am J Neuroradiol 1985; 6: 499-504.

15. O'Connor P. Diagnosis of Central Nervous System Lupus. Can J Neurol Sci 1988; 15: 257-260.

16. Bluestein, H. Neuropsychiatric manifestations of systemic lupus erythematosus. N Engl J Med 1987; 317: 309-311.

17. How A, Dent PB, Liao SK, et al. Antineuronal antibodies in neuropsychiatric systemic lupus erythematosus. Arthritis Rheum 1985; 28: 789-795.

18. Wilson HA, Winfield JB, Rahita RG, et al. Association of IgG antibrain antibodies with central nervous system dysfunction in systemic lupus erythematosus. Arthritis Rheum 1979; 22: 458462.

19. Bresnihan B, Oliver M, Williams B, et al. An antineuronal antibody cross-reacting with erythrocytes and lymphocytes in systemic lupus erythematosus. Arthritis Rheum 1979; 22: 313-320.

20. Bluestein HG. Neurocytotoxic antibodies in serum of patients with systemic lupus erythematosus. Proc Natl Acad Sci 1978; 75: 3965-3969.

21. Levine SR, Welch KMA. Cerebrovascular ischemia associated with lupus anticoagulant. Stroke 1987; 18: 257-263.

22. Atkins CJ, Kondon JJ, Quismorio FP, et al. The choroid plexus in systemic lupus erythematosus. Ann Intern Med 1972; 76: 65-72.

23. Boyer RS, Sun NC, Verity MA, et al. Immunoperoxidase staining of the choroid plexus in systemic lupus erythematosus (abstract). Arthritis Rheum 1978; 21: 547.

24. Hadler NM, Gerwim RD, Frank MM, et al. The fourth component of complement in the cerebrospinal fluid in systemic lupus erythematosus. Arthritis Rheum 1973; 16: 507-520.

25. Keefe EB, Bardana EJ, Harbeck RJ, et al. Antibody to deoxyribonucleic acid (DNA): anti-DNA complexes in cerebrospinal fluid. Ann Intern Med 1974; 80: 58-60. 